\title{
The unwanted response to cardiac surgery: Time for a reappraisal?
}

\author{
David Royston, FRCA ${ }^{a}$ \\ Tomas Kovesi, $\mathrm{PhD}^{\mathrm{a}}$ \\ Nandi Marczin, MD, PhD ${ }^{a, b}$
}

See related article on page 184.
From the Department of Anaesthesia and Critical Care, ${ }^{\text {a }}$ Royal Brompton and Harefield NHS Trust, Harefield Hospital, Harefield, United Kingdom, and the Heart Science Centre, ${ }^{\mathrm{b}}$ Imperial College London, London, United Kingdom.

Received for publication May 28, 2002; revisions requested Aug 14, 2002; revisions received Aug 29, 2002; accepted for publication Sept 12, 2002.

Address for reprints: David Royston, Consultant Anaesthetist, Department of Anaesthesia, Harefield Hospital, Harefield, Middlesex UB9 6JH, United Kingdom (E-mail: dave@tharg.demon.co.uk).

J Thorac Cardiovasc Surg 2003;125:32-5

Copyright $(\odot 2003$ by The American Association for Thoracic Surgery

$0022-5223 / 2003 \$ 30.00+0$

doi: $10.1067 / \mathrm{mtc} .2003 .6$
A scientist must always be absolutely like a child. If he sees a thing, he must say that he sees it, whether it was what he thought he was going to see or not. See first, think later, then test. But always see first. Otherwise you will only see what you are expecting. Most scientists forget that.

-Douglas Adams

So Long, and Thanks for All the Fish

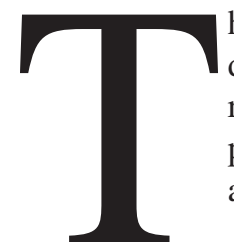

he overwhelming majority of readers of this editorial will be cardiothoracic surgeons. Many may have returned from the operating room knowing they have performed a technically good cardiac procedure and can confidently tell the patient that all went very well and an excellent result is anticipated.

Before leaving the hospital for the day, the reader would like to confirm the patient is warm to the periphery, passing adequate volumes of urine, requiring no inotropic drugs, is extubated, and is talking rationally and coherently with his or her loved ones. A small minority of the patients with no obvious risk or preoperative problems will not have this recovery pattern. These patients may be slow to rewarm, possibly with a mild acidosis. They may require low doses of inotropic agents, regular diuretics to maintain an adequate urine output, and their oxygen transfer may not be quite good enough to allow weaning from the ventilator. This response is never anticipated and is rarely fatal, but it slows the progress of the patient's recovery and is usually attributed to an abnormal inflammatory response to the operation.

The term systemic implies that the normally localized and integrated hemostatic and immune response to trauma or invasion ${ }^{1}$ has become unleashed on the whole body. The extracorporeal system (and sometimes its driver) usually takes the blame for this!

The definition of systemic inflammatory response syndrome (SIRS) includes tachycardia and tachypnea with changes in temperature and white blood cell count. ${ }^{2}$ However, this definition is not altogether helpful in patients having cardiovascular surgery since most patients will be receiving not only positive-pressure ventilation (removing the respiratory component of the definition) but also $\beta$-adrenoceptor blocking agents (reducing confidence in the definition of tachycardia). Many patients after cardiac surgery will have temperatures approaching $38^{\circ} \mathrm{C}$ and white counts in the 11 to $12 \times 10^{9} / \mathrm{L}$ range. However, if the patient is orientated, warm, well-perfused, and passing adequate volumes of urine, he or she is considered as following a normal postoperative course. It is axiomatic that if you, the reader, had leukocytosis, a mild pyrexia, and possibly a degree of nausea then you would consider yourself abnormal, if not downright ill.

Herein lies the crux of the matter. How can we distinguish the normal "physiologic" response from an abnormal, possibly pathologic process when the variable is likely on a continuum? The way this has been largely approached in the past is 
to ignore the clinical signs and symptoms and simply publish the biochemical data showing a benefit, or not, of the therapeutic approach under investigation.

Starting with the seminal work of the team in Alabama, ${ }^{3}$ there has been considerable progress in identifying and documenting changes in putative mediators of an "abnormal" response. The panoply of initiators, amplifiers, and effectors of the inflammatory response has in turn become the focus of attention of the SIRS sleuth. As a consequence, there is a constant supply of manuscripts supporting or refuting a particular maneuver as having a major impact on the inflammatory response.

In this issue of the Journal, Schmartz and colleagues ${ }^{4}$ report a study that failed to demonstrate any effects of aprotinin on plasma concentrations of certain cytokine and complement fragments. The authors conclude that "aprotinin ... has no significant influence on the systemic inflammatory response, as assessed by the mediators measured."

This raises a number of questions related to the potential of this kind of study in aiding our understanding of adverse outcomes related to cardiovascular surgery and the effects of interventions on these unwanted events.

A critical appraisal of this approach needs to address many issues, and only three will be discussed here. First, is there evidence to show the modern extracorporeal system is the primary and singular initiator of the problem? Second, what clinically useful information is obtained by knowing the absolute values of the chosen mediators alone? Finally, what do we want a therapeutic intervention to achieve in relation to this abnormal biochemistry?

\section{Is There Epidemiologic Evidence That Extracorporeal Systems Enhance Adverse Outcome?} Large-scale epidemiologic studies have failed to show time of bypass ( $<90-120$ minutes) as a specific or independent risk factor for the likelihood of dying, ${ }^{5}$ having respiratory, ${ }^{6}$ renal, ${ }^{7}$ or abdominal complications, ${ }^{8}$ or having a deep sternal wound infection. ${ }^{9}$ These studies encompass nearly 100,000 procedures.

Further evidence that supports the notion that extracorporeal circulation alone is not the initiator of subsequent problems comes from novel studies in which coronary surgery was done without bypass. As an example, Hernandez and colleagues ${ }^{10}$ reported on 7867 patients having myocardial revascularization of whom 1741 were operated on without bypass. Results for mortality and morbidity (apart from incidence of atrial fibrillation) were not different between management strategies. Taken together, the epidemiologic data do not support the concept of extracorporeal circulation as the principal villain of the piece but suggest that bypass is safe for the majority of patients.

However, this conclusion does not exclude the possibility that patients who do less well have an exaggerated response to the period of surgery and bypass. There is certainly evidence for great variability in the response of the fibrinolytic system to surgery and bypass and the response of individuals to a given inflammatory stimulus. ${ }^{11}$ The major research challenge in the sphere of the inappropriate inflammatory response remains the identification of those factors (whether genotypic or phenotypic) contributing to this increased susceptibility. In the article under discussion, a patient had excess endotoxin in the plasma, but without detrimental effect. Does this observation imply that endotoxemia alone is not pivotal in the genesis of an unwanted outcome?

\section{Is There Consistent Evidence That a Specific Mediator Is Causally Associated With Adverse Outcome?}

The earliest villain in the bypass-related inflammatory response was suggested as activation of complement. ${ }^{3} \mathrm{Al}-$ though these early studies showed convincing evidence for the role of active fragments in adverse outcomes, activation of complement has now been superseded in the literature by other (more recently discovered) markers. The trend away from the role of complement activation may simply reflect that the modern bypass system does not induce such activity. For example, the study by Schmartz and associates shows no change in activated fragments of C3 or C5 (Article Table 1) and a decrease in $\mathrm{C} 4$ activation (Article Figure 2) with the extracorporeal system they used.

Continuing research searching for the mediator of the bypass-related inflammatory response has produced a vast amount of biochemical data on an array of potential culprits.

Cytokines are the principal inflammatory marker reported by Schmartz and colleagues.

Whereas, at low concentrations, cytokines seem to be essential for optimal function of the defense and repair systems of the body, the higher concentrations of cytokines measured in association with sepsis, trauma, and heart surgery are singled out as deleterious. The protagonists of this belief suggest modulating this response will be of benefit to the patient. The question therefore is whether the evidence consistently supports this notion.

\section{What Should We Measure?}

More than 140 cytokines and chemokines have been recognized in nature. Indeed, one manufacturer of test kits has cytokines, chemokines, and growth factors organized into a "periodic table" on the basis of their producing and target cell. This makes the choice of which "culprit" to measure somewhat of a lottery.

The multifaceted activity of tumor necrosis factor (TNF) (and possibly the fact that the kit for measurement in blood was one of the first commercially available!) makes this a focal target for investigation. Unfortunately, there are as many studies that show TNF concentrations rise in associ- 
ation with heart surgery as there are those failing to demonstrate this effect. This lack of consistent response to a massive and totally unphysiologic stimulus, such as a period of extracorporeal circulation, suggests that TNF alone is not pivotal to the genesis of an adverse outcome and may be a poor marker for such an outcome.

\section{When Should We Measure It?}

In addition to whether a response is present or absent, the timing of that response must be considered. The current study by Schmartz suggests the peak in interleukin 8 (IL-8) concentration is some 4 hours after bypass. This timing is supported by the data of Paugam and colleagues ${ }^{12}$ after normothermic bypass. However, the majority of studies have measured the peak in IL- 8 concentration at the end of surgery or shortly after the release of the aortic crossclamp. In the search for causal relationships between inflammatory markers and outcome, this disparity suggests that a peak or trough can be easily missed.

\section{Does a Rise in a Proinflammatory or Fall in} Antiinflammatory Cytokine Always Predict or Produce an Adverse Outcome?

A National Library of Medicine database search flags over 1500 publications on the topic of cytokines and heart surgery. Only a handful of these relate their data to an index of patient outcome. The data presented in this issue are also not overwhelming in demonstrating a causal relationship between a rise in concentration of a specific cytokine and an adverse outcome. The literature from a more general practice is also not comprehensive, even with a relatively loose definition of SIRS. Antonelli13 ${ }^{13}$ reviewed 89 clinical papers published between 1993 and 1997 on the role of cytokines during sepsis and other inflammatory reactions. Cytokines were analyzed in more than 5000 patients. Fifty $(62 \%)$ of the 80 studies that investigated a correlation between cytokine concentration and outcome found the concentrations of cytokines did not predict death. The rest of the $30(48 \%)$ investigations depicted an inhomogeneous picture: even though 27 studies evidenced higher levels of cytokines in nonsurvivors, 3 studies found the opposite.

It is becoming increasingly apparent that the more-isworse therefore less-is-better thinking may not be appropriate in all circumstances. In severe inflammatory states, such as found with septicemia and meningococcal disease, increased mortality is associate with a lack of TNF response and an exaggerated IL-10 effect. ${ }^{14,15}$ This pattern has also been shown in a separate study of 464 consecutive patients admitted to the hospital with fever $\left(\geq 38.2{ }^{\circ} \mathrm{C}\right) .{ }^{16}$ Concentrations of IL-10 were significantly higher in the blood of the 33 patients who died compared with that of survivors. These data suggest that interventions intended to suppress the "proinflammatory" (such as TNF) and augment the "anti-inflammatory" (eg, IL-10) response may not have the intended effect on outcome. It is apparent that any change, or lack of it, in a particular cytokine concentration is not always a good marker of an adverse outcome or disease in the patient. This leads to the final question raised by the study by Schmartz and colleagues.

\section{What Do We Want a Therapeutic Intervention to Achieve and How Can This Be Related to Abnormal Biochemistry?}

The holy grail of the SIRS sleuth is to find a way to block or inhibit the "badness," thereby allowing good to prevail. Reducing the biologic activities of IL-1 and TNF has been accomplished by several different, but highly specific, strategies, which involve neutralizing antibodies, soluble receptors, and receptor antagonists. Thus far, attempts to block IL-1 or TNF have been spectacularly unsuccessful in human beings with sepsis. Agents such as TNF-neutralizing antibodies, soluble TNF receptors, and IL-1 receptor antagonist have been infused into more than 10,000 patients in doubleblind, placebo-controlled trials. Although there has been a consistent small increase $(2 \%-3 \%)$ in 28 -day survivals with anticytokine therapy, the effect has not reached statistical significance. ${ }^{17}$

In contrast, a recent meta-analysis showed that patients having heart surgery who received high-dose aprotinin therapy had a significant, 2-fold reduction in mortality compared with patients in the placebo or control arm of the studies examined. ${ }^{18}$ The exact reason why the use of aprotinin therapy is associated with a reduced mortality is currently opaque. Aprotinin has many potential benefits in terms of modulating the inflammatory response, ${ }^{19,20}$ but these are not consistently reported and may be dependent on dose.

The confusion surrounding the role of the panoply of biochemical markers in an adverse outcome is not related only to cytokine responses. Similar arguments can be made for virtually all of the "inflammatory markers" reported in the literature and apply to aprotinin as well. For example, in a study investigating the influence of aprotinin on oxidant stress and neutrophil cytotoxicity using a cell culture system, decrease in neutrophil-associated cell death was observed with aprotinin but neutrophil respiratory burst, reflecting neutrophil oxidant output, was enhanced by this intervention. ${ }^{21}$ These data can be used by the protagonists of aprotinin therapy to show a benefit (reduced toxicity) or by the antagonists to show a potentially deleterious effect (increased oxidant stress).

Where can we go from here? The first logical step is to persuade investigators to stop considering biochemistry in isolation. If the biochemistry is not in some way related to a simple outcome measure, is it really of any clinical, as opposed to intellectual interest? An important and as yet not clearly defined question is, what are the clinically relevant end points? The obvious suggestion is a patient in a state 
that makes the responsible physician feel comfortable. If the patient is warm, passing urine, requiring no inotropic drugs, breathing spontaneously without distress, and talking rationally and coherently, does it matter that he or she has a raised "something we have an assay for and can measure?" So far, the isolated biochemical approach has not proved of any obvious benefit in helping us predict or understand nonfatal complications. Is it time to have a rethink on the strategy of investigating potential interventions or markers by first defining whether they are associated with improvements or worsening of patient outcomes?

The 50th anniversary of the successful use of the heartlung machine will be in May of 2003. Many lives have been saved and their quality improved because of this innovation; some have also been lost or the quality reduced. It may be wishful thinking, but by this anniversary it should not be beyond the clinical and scientific communities involved in cardiothoracic surgery to decide on a core group of patientoriented end points to allow us to define an appropriate or inappropriate outcome. These criteria can then be used by all investigators to ensure that their studies and data can be related to the patient in addition to the test tube. The suggestion that the patient is warm to the periphery, passing adequate volumes of urine, requiring no inotropic agents, and is extubated and talking rationally and coherently within a period of time from the end of surgery is what every clinician anticipates for the patient and therefore seems a good place to start.

\section{References}

1. Royston D. The evolution of coagulation and inflammation. In: Spiess $\mathrm{BD}$, editor. The relationship between coagulation, inflammation and the endothelium-A pyramid towards outcome. A Society of Cardiovascular Anesthesiologists monograph. Philadelphia: Lippincott Williams \& Wilkins; 2000. p 1-30.

2. Muckart DJ, Bhagwanjee S. American College of Chest Physicians/ Society of Critical Care Medicine Consensus Conference. Definitions of the systemic inflammatory response syndrome and allied disorders in relation to critically injured patients. Crit Care Med. 1997;25:178995 .

3. Kirklin JK, Westaby S, Blackstone EH, Kirklin JW, Chenoweth DE, Pacifico AD. Complement and the damaging effects of cardiopulmonary bypass. J Thorac Cardiovasc Surg. 1983;86:845-57.
4. Schmartz D, Tabardel Y, Preiser J-C, Barvais L, d'Hollander A, Duchateau J, et al. Does aprotinin influence the inflammatory response to cardiopulmonary bypass in patients? J Thorac Cardiovasc Surg. 2003;125:184-90.

5. Roques F, Nashef SA, Michel P, Gauducheau E, de Vincentiis C, Baudet E, et al. Risk factors and outcome in European cardiac surgery: analysis of the EuroSCORE multinational database of 19030 patients. Eur J Cardiothorac Surg. 1999;15:816-23.

6. Christenson JT, Aeberhard JM, Badel P, Pepcak F, Maurice J, Simonet $\mathrm{F}$, et al. Adult respiratory distress syndrome after cardiac surgery. Cardiovasc Surg 1996;4:15-21.

7. Chertow GM, Levy EM, Hammermeister KE, Grover F, Daley J. Independent association between acute renal failure and mortality following cardiac surgery. Am J Med. 1998;104:343-8.

8. Tsiotos GG, Mullany CJ, Zietlow S, van Heerden JA. Abdominal complications following cardiac surgery. Am J Surg. 1994;167:553-7.

9. Stahle E, Tammelin A, Bergstrom R, Hambreus A, Nystrom SO, Hansson HE. Sternal wound complications: incidence, microbiology and risk factors. Eur J Cardiothorac Surg. 1997;11:1146-53.

10. Hernandez F, Cohn WE, Baribeau YR, Tryzelaar JF, Charlesworth DC, Clough RA, et al. In-hospital outcomes of off-pump versus on-pump coronary artery bypass procedures: a multicenter experience. Ann Thorac Surg. 2001;72(5):1528-34.

11. Chandler WL, Fitch JC, Wall MH, Verrier ED, Cochran RP, Soltow $\mathrm{LO}$, et al. Individual variations in the fibrinolytic response during and after cardiopulmonary bypass. Thromb Haemost. 1995;74:1293-7.

12. Paugam C, Chollet-Martin S, Dehoux M, Chatel D, Brient N, Desmonts JM, et al. Neutrophil expression of CD11b/CD18 and IL-8 secretion during normothermic cardiopulmonary bypass. J Cardiothorac Vasc Anesth. 1997;11:575-9.

13. Antonelli M. Sepsis and septic shock: pro-inflammatory or anti-inflammatory state? J Chemother. 1999;11:536-40.

14. Lehmann AK, Halstensen A, Sornes S, Rokke O, Waage A. High levels of interleukin 10 in serum are associated with fatality in meningococcal disease. Infect Immunol. 1995;63:2109-12.

15. Westendorp RG, Langermans JA, Huizinga TW, Elouali AH, Verweij CL, Boomsma DI, et al. Genetic influence on cytokine production and fatal meningococcal disease. Lancet. 1997;349:170-3.

16. van Dissel JT, van Langevelde P, Westendorp RG, Kwappenberg K, Frolich M. Anti-inflammatory cytokine profile and mortality in febrile patients. Lancet. 1998;351:950-3.

17. Dinarello CA. Proinflammatory cytokines. Chest. 2000;118:503-8.

18. Levi M, Cromheecke ME, de Jonge E, Prins MH, de Mol BJ, Briet E, et al. Pharmacological strategies to decrease excessive blood loss in cardiac surgery: a meta-analysis of clinically relevant endpoints. Lancet. 1999;354:1940-7.

19. Royston D. Serine protease inhibition prevents both cellular and humoral responses to cardiopulmonary bypass. J Cardiovasc Pharmacol. 1996;27(Suppl 1):S42-9.

20. Mojcik CF, Levy JH. Aprotinin and the systemic inflammatory response after cardiopulmonary bypass. Ann Thorac Surg. 2001;71:74554.

21. Wang JH, Redmond HP, Watson RW, Duggan S, McCarthy J, Barry $\mathrm{M}$, et al. Mechanisms involved in the induction of human endothelial cell necrosis. Cell Immunol. 1996;168:91-9. 